\title{
Commentary
}

\section{How can Medical Education Support the Current Healthcare Initiatives in Singapore?}

Zhong Hao Chia, ${ }^{1}$, Choon Seng Chong, ${ }^{1,2}$ MBBS (S'Pore), MRCS (Ed), FRCS (Ed), Gominda Ponnamperuma, ${ }^{3}$ MBBS (Colombo), MMEd (Dundee), PhD, Dujeepa Samarasekera, ${ }^{3}{ }_{M B B S,}$, MHPE, FAMS

The current undergraduate medical education landscape in Singapore is changing. With the newest medical school, Lee Kong Chian School of Medicine (LKCSOM) established, Nanyang Technological University accepting its sixth batch of medical students in 2018 , the total number of newly graduated doctors entering the workforce is at an all-time high. In the academic year 2017/2018, there were a total of 2243 medical students in the 3 Singapore medical schools: National University of Singapore (NUS) with 1515 students in 5 batches, Duke-NUS Medical School with 281 students in 4 batches, and LKCSOM with 447 students in 5 batches. ${ }^{1,2}$ In comparison, in academic year 2006/07, before the launch of Duke-NUS, there were only 1188 students in total. This represents almost a doubling of numbers in a span of 10 years, and as such may present as a challenge for training opportunities.

Additionally, we have witnessed 2 recent trends in healthcare in Singapore.

First is the trend signalling a shift from hospital (i.e., specialist care) to community care (i.e., generalist or primary care) by the Ministry of Health $(\mathrm{MOH})$, Singapore. In the literature, the terms "Primary Care", "Generalist", "Family Physician", "General Practice" are found to be used interchangeably in different parts of the world. However, in Singapore they have distinct meanings-Family Physician (FP) is a person who has College membership through training (MMed diploma or with Fellowship); General Practitioner (GP) is a person practising in a private clinic with a basic medical degree such as MBBS or MD without formal postgraduate training. Hence, in the Singapore context, both the Family Physician and the General Practitioner represent the 'community' with regards to the shift mentioned.

Second is MOH's review of postgraduate residency programmes ${ }^{3}$ to focus on improving care to the aging population by training more generalist doctors, with improved training to tackle diseases of more than one body part or organ. As part of the curricular quality assurance process, $\mathrm{MOH}$ had also conducted a review and recommended some changes to the current Accreditation Council for Graduate Medical Education International (ACGME-I) residency programme. ${ }^{3}$

This is a significant departure from the previous system of postgraduate programme. In 2010, MOH introduced the postgraduate programme based on the North American ACGME-I residency training format. This was done to streamline residency training by providing a systematic structure and to reduce the waiting time for doctors to enter into specialist programmes. However, some believe that this may have created a situation where there are too many specialist doctors for hospital positions. Interviews with senior doctors have also suggested that this system of residency programme has reduced interest in primary care and generalist programmes, leading to a disparity between specialists and generalists. ${ }^{4}$ Some have opined that specialists are perceived to be better paid and have shorter working hours compared to generalists. Others have indicated that medical professionals and even medical students underestimate the capabilities and importance of generalists, specifically Family Physicians. This might be especially true for medical students, who suffer from a lack of working experience, or misinformation. Being in the safe confines of medical school might also shield medical students from the reality of this primary care push and the possible market forces at play. ${ }^{5}$

When dealing with such a situation, what can we learn from the rest of the world? Similarities can be drawn between Singapore's present situation and that of the United States. In the 1990s, there was a disparity between the number of generalists and the number of

\footnotetext{
NUS Yong Loo Lin School of Medicine, National University of Singapore, Singapore

${ }^{2}$ Division of Colorectal Surgery, Department of Surgery, Surgical University Cluster, National University Hospital, Singapore

${ }^{3}$ Centre for Medical Education (CenMED), NUS Yong Loo Lin School of Medicine, National University of Singapore, Singapore

Address for Correspondence: Chia Zhong Hao, NUS Yong Loo Lin School of Medicine NUHS Tower Block, 1E Kent Ridge Road Level 11, Singapore 119228.

Email: zhonghao94@hotmail.com
} 
specialists, with the American Government looking to shift its focus from specialist care to primary care or generalist care. Suggestions offered during their shift towards primary care included designating specific medical schools with a primary care-focused curriculum, changing the admissions process to allow more students interested in primary care into medical school, allowing primary care practitioners to chair the admissions process, providing role models from the primary care sectors throughout medical school, and offering more support for primary care practitioners. ${ }^{6}$ Emphasis on primary care has to start from admissions, as studies have shown that a students' initial career preference is an important indicator of what they eventually pursue as a career, ${ }^{7}$ and any changes in preference are usually from primary care to specialist care. ${ }^{8}$ Of course, considering the number of medical schools in the U.S. compared to Singapore, suggestions such as a designated primary care medical schools would not be feasible in Singapore. However, if the shift of focus to primary care were to succeed, some form of change in curriculum, as well as the admissions process seems to be necessary. More importantly, increased support for GPs during their practice would make a big difference. In fact, the Affordable Care Act in the U.S. included provisions such as bonuses for primary care providers. ${ }^{9}$

Other studies in the U.S. have also shown that up to half of students who have the intention to pursue generalist careers at the point of matriculation into medical school retain interest, and twice that number acquire an interest during their basic medical education. ${ }^{10}$ This was postulated in the past to be due to greater emphasis on primary care in the medical school and the changes in health care delivery. In the current push towards primary care, this effect might be seen in Singapore as well.

In a study of medical students from a Canadian medical school, students expressed concern about the general public's negative bias towards family physicians. ${ }^{11}$ In the U.S. in the 1990s, many similar concerns regarding primary care, in economics, academics, and behaviour ${ }^{12}$ were raised, and many of these concerns are still present. Although there are no studies showing this problem in Singapore, the problem could be present in Singapore. Hence, although emphasis must be placed on changing the public perception of GPs and FPs, some focus must also be placed on changing medical students' perceptions. This problem could potentially become a case of a self-fulfilling prophecy: those who did not want to be a GP due to negative perception ended up having no choice but to be a GP and their unchanged negative perception of what a GP is like influences their practice. Ultimately instead of actively trying to change the public perception, their negative practice continues the negative public perception of GPs.

In addition, many studies were conducted in the U.S., looking into factors influencing specialty choice in graduates and how best to boost the primary care specialty take-up rates. ${ }^{5,9,10}$ These studies offered recommendations that might have indirectly served as a feedback mechanism to the policy changes in the U.S. Within a short span of a few years, family medicine and generalist tracks became the top choice of residency programme among graduates. At present, there has already been a significant increase in the number of medical students in America, and an increasing reliance on foreign graduates $;{ }^{13}$ yet there are still increasing workforce shortages in both primary care and specialty care. ${ }^{14}$ Deans of medical schools have even expressed concerns about the availability of residency training positions, ${ }^{15}$ with some suggesting that these shortages would not have been present if the specialist residency programmes were not capped 30 years ago. ${ }^{16}$

In Singapore, published studies are centered around what factors influence medical student choices for specific specialties like emergency medicine ${ }^{17}$ and psychiatry, or focusing on the impact of a specific factor like debt on specialty choice, ${ }^{18}$ or factors affecting the choice of a sponsoring institute. ${ }^{19}$ While these studies are essential for programme directors of these specialties, it is not relevant to understanding what current medical students feel about the current medical education and healthcare trends. Factors found to affect the choice of specialty, and sponsoring institute in local studies ${ }^{17,19}$ were largely similar to those found in overseas studies. ${ }^{21}$ Some of these factors were seen to be important to students choosing a primary care career, and perhaps these factors could be highlighted specifically by faculties trying to encourage students towards a primary care career.

The trends in the medical education landscape may have created diverse views among the current medical students on their current and future training prospects. In fact, there have been signs of these changes being implemented. Residency training positions offered in the generalist fields such as internal medicine, family medicine, or geriatrics begin to make up a larger proportion of the overall training 
slots, increasing from $12 \%$ in $2013^{3}$ to $20 \%$ in 2017 , and latest data from 2018 shows that more than $50 \%$ of residency training positions offered were in these mentioned fields. ${ }^{20}$

Every country has its unique healthcare challenges, and although many of the themes are recurring throughout the world, en bloc incorporation of other countries' systems would not provide a good fit for Singapore. Instead, taking inspiration from the best elements from around the world to build a holistic Singaporean medical education system would allow the best chance for a fit. The generalist mindset has to be propagated also, where even a broader practice mindset within a specialist field would be beneficial to the patient.

The aforesaid changes, currently being implemented in Singapore, may breed uncertainty and cause unnecessary stress on the new generation of doctors. This can result in burnout or a diminishing workforce in the future. Finding and addressing the students' concerns through deliberate intervention during medical school such as training, policies, and most importantly, dialogue, could aid in achieving the planned national policy directives in healthcare without any negative consequences.

\section{Acknowledgements}

The authors thank Dr Lee Shuh Shing, Medical Educationalist of CenMED, National University of Singapore, Yong Loo Lin School of Medicine for her contribution and revision of the manuscript.

\section{REFERENCES}

1. National University of Singapore. Summary of undergraduate student enrolment. Available at: http://www.nus.edu.sg/registrar/docs/info/ student-statistics/enrolment-statistics/undergraduate-studies/ugenrol-20172018.pdf. Accessed on 11 August 2020.

2. Nanyang Technological University Singapore. Undergraduate population from AY2010-11 to AY2019-20. Available at: https:// www.ntu.edu.sg/AboutNTU/CorporateInfo/FactsFigures/Pages/ undergraduatepopulation2010-19.aspx. Accessed on 11 August 2020.

3. Yusof ZM. MOH reviews doctors' training to become specialists. The Straits Times, 1 October 2017. Available at: https://www.straitstimes. com/singapore/health/moh-reviews-doctors-training-to-becomespecialists. Accessed on 7 August 2019.

4. Ng K. The Big Read: Specialists or GPs? Training review to get mix right is just what the doctor ordered. TODAYonline, 20 October 2017. Available at: https://www.todayonline.com/singapore/ big-read-specialists-or-gps-training-review-get-mix-right-just-whatdoctor-ordered. Accessed on 7 August 2019.

5. Altman DF. Medical student career choice: ill the market provide the solution to our health care workforce needs? Am J Med 1994;97:407-9.

6. Urbina C, Hickey M, Mcharney-Brown C, Duban S, Kaufman A. Innovative generalist programs: academic health care centers respond to the shortage of generalist physicians. J Gen Intern Med 1994;9:S81-9

7. Wright B, Scott I, Woloschuk W, Brenneis F, Bradley J. Career choice of new medical students at three Canadian universities: family medicine versus specialty medicine. CMAJ 2004;170:1920-4. Erratum in: CMAJ 2004;171:1327.

8. Bland CJ, Meurer LN, Maldonado G. Determinants of primary care specialty choice: a non-statistical meta-analysis of the literature. Acad Med 1995;70:620-41.

9. Rawls L, Perry RF. Health care reform and graduate medical education. N Engl J Med 1994;331:879-80.

10. Kassebaum DG, Szenas PL. Specialty intentions of 1995 U.S. medical school graduates and patterns of generalist career choice and decision making. Acad Med 1995;70:1152-7.

11. Pianosi K, Bethune C, Hurley KF. Medical student career choice: a qualitative study of fourth-year medical students at Memorial University, Newfoundland. CMAJ Open 2016;4:E147-52.

12. Petersdorf RG. Primary care applicants--they get no respect. N Engl J Med 1992;326:408-9.

13. Carroll AE. Why America needs foreign medical graduates. The New York Times, 6 October 2017. Available at: https://www.nytimes. com/2017/10/06/upshot/america-is-surprisingly-reliant-on-foreignmedical-graduates.html. Accessed on 7 August 2019.

14. Heiser S. New findings confirm predictions on physician shortage. AAMC News, 23 April 2019. Available at: https://news.aamc.org/ press-releases/article/2019-workforce-projections-update/. Accessed on 7 August 2019.

15. U.S. medical school enrollment surpasses expansion goal. AAMC News, 25 July 2019. Available at: https://news.aamc.org/press-releases/ article/us-medical-school-enrollment-surpasses-goals/. Accessed on 7 August 2019.

16. Cooper RA. Unraveling the physician supply dilemma. JAMA 2013;310:1931-2.

17. Chew SH, Ibrahim I, Yong YZ, Shi LM, Zheng Qs, Samarasekera DD, et al. Factors influencing the decision to pursue emergency medicine as a career among medical students in Singapore. Singapore Med J 2018;59:126-32.

18. Fong JMN, Tan YTW, Sayampanathan AA, Mohan N, Koh YQ, Jang JHJ, et al. Impact of financial background and student debt on postgraduate residency choices of medical students in Singapore. Singapore Med J 2018;59:647-51.

19. Ng CL, Liu XD, Murali Govind R, Tan JWJ, Ooi SBS, Archuleta S. Factors affecting choice of sponsoring institution for residency among medical students in Singapore. Singapore Med J 2018;59:642-46.

20. Ministry of Health Holdings. Residency match results 2 July 2019. Available at: http://www.physician.mohh.com.sg/Documents/July2019-Match-Results.pdf. Accessed on 7 August 2019. 